\title{
Model of the Surface-to-Air Missile System Reliability during Long-Term Operation
}

\author{
V.V. Lukianchuk ${ }^{1}$, B.N. Lanetskii ${ }^{1}$, I.V. Koval ${ }^{1}$, P.V. Open'ko ${ }^{2 *}$, \\ V.V. Tyurin ${ }^{2}$ and V.V. Khoma ${ }^{2}$ \\ ${ }^{1}$ Air Force Research Laboratory, Kharkiv National Air Force University named after Ivan \\ Kozhedub, Kharkiv, Ukraine \\ ${ }^{2}$ Institute of Aviation and Air Defense, National Defense University of Ukraine named after \\ Ivan Cherniakhovskyi, Kyiv, Ukraine
}

\begin{abstract}
The manuscript was received on 17 May 2021 and was accepted after revision for publication as technical information on 14 December 2021.
\end{abstract}

\begin{abstract}
:
During the long-term operation, anti-aircraft missile weapons are characterized by the technical condition and level of reliability change influeincing the efficiency on the intended use. The article presents a model of surface-to-air missile system (SAMS) reliability during long-term operation, which contains a set of models, namely: a model of operation of ground combat assets (GCA) of SAMS according to the typical cyclogram of intended use (TCIU); a reliability dynamics model of SAMS GCA in the established system of maintenance and repair (SMR) and a reliability dynamics model of surface-to-air missiles (SAM) during extended usage. It is expedient to use the developed model at substantiation of requirements to the indicators of SAMS and SAM reliability for their development or modernization; when developing SAMS repair plans in terms of determining the time of SAMS GCA and (or) SAM repairing time and when developing methods for assessing the effectiveness of SAMS taking into account the duration of SAMS GCA and SAMS usage.
\end{abstract}

\section{Keywords:}

coefficient of effectiveness sustainment, long-term operation, SAMS reliability model, surface-to-air missile systems, typical cyclogram of intended use

\section{Introduction}

Modern SAMSs are designed for long-term operation. According to the SAMSs analysis used in many countries, it is established that the duration of their life cycle is

\footnotetext{
* Corresponding author: Research Department of the Institute of Aviation and Air Defense, National Defense University of Ukraine named after Ivan Cherniakhovskyi, Povitroflotsky Prospect 28, UA-03049 Kyiv, Ukraine. Phone: +380667645920, E-mail: pavel.openko@ukr.net.ORCID0000-0001-7777-5101.
} 
more than 30 years. Such SAMSs are characterized by a gradual depletion of resources, deterioration of technical condition and their reliability decrease affecting significantly their efficiency.

Solving the tasks of technical equipment of the armed forces by the SAMS involves solving the tasks of their purchase, development, maintenance in combat readiness, etc. At the same time, it is necessary to solve a set of tasks related to the assessment of the impact of SAMS GCA and SAM components on the efficiency of SAMS operation, namely substantiation of requirements to its GCA reliability indicators and reliability indicators and assigned SAM indicators. In this regard, it is important to develop a model of reliability of SAMS during long-term operation to assess the effectiveness of SAMS.

\section{Definition of Research Problem}

The SAMS is a complex technical system (CTS). Existing and being developed CTSs are mainly designed for long-term operation. In order to ensure the appropriate level of their failure-free operation it is necessary to control technical condition, performance restoration, maintenance, etc., which falls under the responsibility of the maintenance and repair system. Depending on the element that is designed by the manufacturer to ensure the CTS appropriate failure-free operation, there are CTSs, which are checked or non-checked, restored or non-restored, serviceable or non-serviceable, etc. In accordance with this classification, there are CTS reliability models. The following systems of reliability models are based on these features of CTSs maintenance:

- CTSs which are not checked, non-restorable, and non-serviceable,

- CTSs which are checked, restorable, and non-serviceable,

- CTSs which are checked, restorable and serviceable, etc.

Generally, the publications include CTSs reliability models, which arenot checked, non-restorable and non-serviceable and CTSs, which are checked, restored, and non-serviceable.

Thus, the article [1] considers:

- the failure-free operation model, which is presented by exponential-type distribution of operating time to failure, Weibull distribution, and normal distribution,

- the serviceability model, which is represented by exponential-type distribution of performance restoration duration,

- the reliability model of tractor as a vehicle, which is checked, restored, and non-serviceable, in the form of steady-state availability.

The [2] considers the CTS reliability model (by an example of the pipeline system) that is not checked, non-recoverable, and non-serviceable. The process of this CTS failure development is divided in two phases: the defect phase and defect growth phase. Meanwhile, the second phase follows the first one and it is characterized by some duration.

The [3] develops the imitation reliability model of gas transmission network. In this model, the subject of research is non-serviceable and non-restorable. Moreover, the influence of some sub-systems failure and simultaneous failure of two or more sub-systems on failure-free operation and network functioning reliability is researched.

The [4] provides the reliability model of wireless sensor network (WSN) to analyze the influence of failures of field-located in-built facilities. In this case, the 
network functioning process is modelled considering failures of its elements and topology. The modelling subject is restorable and non-serviceable.

The [5] considers the reliability model of electric, electronic and programmable electronic systems designed for prevention and mitigation of consequences of dangerous events at different high-risk facilities in nuclear, refining, oil and gas, chemical, automotive industries. The reliability model is based on Markoff processes concerning subjects which are non-recoverable and non-serviceable.

The design of the above-considered [1-5] CTSs reliability models does not consider the features of typical cyclograms of their maintenance that does not permit to consider all main factors influencing their reliability.

The issue of design of such CTSs reliability models as SAMS taking into account TCIU, is considered in $[6,7]$. In this case, the reliability characteristics are usually considered concerning fixed calendar operation duration at normal operation which is characterized by constant failure rate [8-10]. However, in case of long-term operation when SAMS exceeds a life cycle, it is necessary to solve the issue of their repair or replacement by new ones. It is necessary to consider dependence of reliability indicators on calendar operation duration and other factors [10]. In [11, 12] the influence of the reliability of SAMS mobility on the assessment of the operational and tactical indicator (OTI) the coefficient of effectiveness sustainment of SAMS $K_{\text {eff }}$ is considered. The [10] considers the SAMS effectiveness model where the TCIU parameters are considered. Meanwhile, it is permitted that the reliability model describing SAMS failures and restorations processes at the standby phase of combat operation is known. The influence of periodic SAMS maintenance and functioning control (FC) on reliability is not considered.

Thus, the publications review reveals that problems of reliability models design for CTSs, which are checked, restorable, and serviceable, are duly considered. Particularly, this is the case of SAMS reliability models design considering its TCIU and dynamics of influence on controls reliability. Periodic maintenance, and repair indicators.

Our article develops the SAMS reliability model at long-term operation considering:

- possible operating conditions when SAMS can be put on ready-to-combatoperation mode considering operation modes and other factors. Modelling results permit to evaluate possibilities of SAMS operating or nonoperating conditions in any time at the considered phase, including at combat readiness,

- failure-free dynamics of SAMS GCA considering influence of periodic SAMS maintenance and FC and SAMS failure-free dynamics during calendar operation duration.

This model is designed in order to evaluate and forecast the influence of change of SAMS technical condition and reliability level on effectiveness of its functioning at long-term operation with use of OTI such as $K_{\text {eff }}[13]$. In accordance with [14, 15] the SAMS OTI $K_{\text {eff }}$ [13] represents the ratio of mathematical expectation (ME) of the number of targets destroyed by SAMS, taking into account its technical condition and reliability, to the nominal value of ME, provided that SAMS is operational at the beginning of combat operations and does not fail in the process of functioning during a long-term operation. 


\section{Method Description and Basic Mathematical Equations}

In case of long-term operation, the SAMS reliability model contains a set of models:

- model of operation of SAMS GCA according to TCIU,

- dynamics reliability model of SAMS GCA at the established system of maintenance and repair,

- dynamics reliability model of SAM at a long operation.

Model of operation of SAMS GCA according to TCIU describes possible operating modes in the operating interval considered in relation to the moment $t_{\mathrm{e}}-$ calendar time in service. At the same time, three stages of SAMS operation are considered.

At the first stage, the operation of SAMS is as follows: SAMS is in working condition and ready for a combat use. Duration performance controls $t_{\mathrm{pc}}$ are carried out with a regular period $T_{\mathrm{pc}}[16,17]$. When switching on SAMS, conducting PC, switching off, being off, failures can occur, which are detected in functioning control. In this case, SAMS goes into the state of recovery, which ends with PC and subsequent switching off SAMS under the condition of its operational state. Duration maintenance $t_{\mathrm{m}}$ is carried out with a regular period $T_{\mathrm{m}}$. Failures may occur during maintenance procedures. At the same time, maintenance is suspended for the period of recovery. Otherwise, maintenance is completed by carrying out of PC, as a result of which SAMS is switched off at its working condition or it goes into a state of recovery in the opposite case.

At the second stage, SAMS is in a standby mode and switched on state from the moment of the entry of the signal for a combat readiness use until the moment of receiving guideline to destroy the target. In case of inoperability, SAMS is in the mode of recovery.

At the third stage, SAMS is in a combat mode provided that it is operational at the time of receiving of the guideline. The intended use of SAMS will be successful in case of failure-free operation.

SAMS GCA has a specific feature which enables it to be in a standby mode of combat operations with periodic PC for a long time. In this case, SAMS GCA can often be turned on, be on state for a short or long time, turned off and be off state, as well as be in a combat mode. Each of these states is characterized by a corresponding failure rate at the current moment $t_{\mathrm{e}}$, which, taking into account the modes of operation [13], is determined as follows:

$$
\lambda\left(t_{\mathrm{e}}\right)=\left(1-k_{\mathrm{ie}}\right) \lambda_{\text {off }}\left(t_{\mathrm{e}}\right)+k_{\mathrm{ie}} \lambda_{\text {on }}\left(t_{\mathrm{e}}\right)+\lambda_{\mathrm{y}}\left(t_{\mathrm{e}}\right) f_{\mathrm{y}}
$$

where $k_{\mathrm{ie}}$ - the coefficient of exploitation intensity (a ratio of the duration of SAMS on state to the duration of operation); $\lambda_{\text {off }}\left(t_{\mathrm{e}}\right), \lambda_{\mathrm{on}}\left(t_{\mathrm{e}}\right)$ - the failure rates off and on state, respectively; $\lambda_{\mathrm{y}}\left(t_{\mathrm{e}}\right)$ - the intensity of failures at turning on (the number of failures when one is switching on); $f_{\mathrm{y}}-$ the switching frequency.

Dependences $\lambda_{\text {off }}\left(t_{\mathrm{e}}\right), \lambda_{\text {on }}\left(t_{\mathrm{e}}\right)$ from the duration of operation for the GCA can be constructed from the results of point estimates of the failure rate parameter $\omega\left(t_{\mathrm{e}}\right)$ for different $t_{\mathrm{e}}$ under the assumption of a nonstationary Poisson flow $\omega\left(t_{\mathrm{e}}\right)=\lambda\left(t_{\mathrm{e}}\right)$. These dependences are constructed in the form of a paired regression dependence $[10,17]$ :

$$
\lambda_{\mathrm{on}}\left(t_{\mathrm{e}}\right)=a_{0}+a_{1} t_{\mathrm{e}}+\ldots+a_{i} t_{\mathrm{e}}^{i}
$$

where $a_{0}, a_{1}, \ldots, a_{i}$ - polynomial coefficients.

It should be noted that taking into account the operating conditions, $\lambda_{\text {off }}\left(t_{\mathrm{e}}\right)$ is found by the ratio: 


$$
\lambda_{\text {off }}\left(t_{\mathrm{e}}\right)=\alpha \lambda_{\text {on }}\left(t_{\mathrm{e}}\right)
$$

where $\alpha-$ the service factor [18].

The dependence $\lambda_{\mathrm{y}}\left(t_{\mathrm{e}}\right)$ can be calculated as follows:

$$
\lambda_{\mathrm{y}}\left(t_{\mathrm{e}}\right)=-\ln \left[P_{y}\left(t_{\mathrm{e}}\right)\right]
$$

where $P_{\mathrm{y}}\left(t_{\mathrm{e}}\right)$ - the dependence of the probability of failure-free switching GCA from $t_{\mathrm{e}}$, which can also be constructed based on the results of point estimates during long-term operation in the form of a paired regression dependence [17]:

$$
P_{\mathrm{y}}\left(t_{\mathrm{e}}\right)=b_{0}+b_{1} t_{\mathrm{e}}+\ldots+b_{j} t_{\mathrm{e}}^{j}
$$

where $b_{0}, b_{1}, \ldots, b_{j}-$ polynomial coefficients.

In accordance with the described stages, there are considered in the model the following SAMS GCA possible operational states during the operation interval equal to the maintenance cycle:

- $\mathrm{E}_{1}$ - off, combat standby,

- $\mathrm{E}_{2}-$ on, performance monitoring,

- $\mathrm{E}_{3}-$ on, performance restoration,

- $\mathrm{E}_{4}-$ on, training, combat work,

- $\mathrm{E}_{5}-$ on, maintenance.

In this case the maintenance cycle is understood as the smallest repeated time interval, during which all the established types of maintenance are performed in the sequence established by the regulatory documents.

Concerning the above-mentioned TCIU phases, the probabilities of any SAMS GCA $E_{i}$ state can be estimated as the ratio of the total time spent by ground combat assets of the anti-aircraft missile system in the $\mathrm{E}_{\mathrm{i}}$ state for the maintenance cycle relative to the moment $t_{\mathrm{e}}-t_{\Sigma_{i}}\left(t_{\mathrm{e}}, \mathrm{T}_{\mathrm{c}}\right)$ and the duration of the maintenance cycle $-T_{\mathrm{c}}$, that is:

$$
P_{\mathrm{E} i}\left(t_{\mathrm{e}}, T_{\mathrm{c}}\right)=\frac{t_{\sum i}\left(t_{\mathrm{e}}, T_{\mathrm{c}}\right)}{T_{\mathrm{c}}}, i=1,2, \ldots, 5
$$

In this case, the integrated time of SAMS GCA in each of the states at $T_{\mathrm{c}}$ relative to the $t_{\mathrm{e}}$ moment is calculated as follows:

in the $\mathrm{E}_{3}$ state:

$$
t_{\Sigma 3}\left(t_{\mathrm{e}}, T_{\mathrm{c}}\right)=\left[\lambda\left(t_{\mathrm{e}}-\frac{T_{\mathrm{c}}}{2}\right)+\lambda\left(t_{\mathrm{e}}+\frac{T_{\mathrm{c}}}{2}\right)\right] T_{\text {art }}\left(t_{\mathrm{e}}\right)
$$

where $T_{\text {art }}\left(t_{\mathrm{e}}\right)$ - the average recovery time of the SAMS,

in the $\mathrm{E}_{4}$ state:

$$
t_{\Sigma 4}\left(t_{\mathrm{e}}, T_{\mathrm{c}}\right)=\frac{T_{\mathrm{c}}}{T_{\mathrm{tr}}} t_{\mathrm{tr}}+t_{\mathrm{cw}}\left(t_{\mathrm{e}}, T_{\mathrm{c}}\right)
$$

where $T_{\mathrm{tr}}, t_{\mathrm{tr}}-$ the frequency and duration of training respectively; $t_{c w}\left(t_{\mathrm{e}}, \mathrm{T}_{\mathrm{c}}\right)-$ duration of combat work at $T_{\mathrm{c}}$.

The reliability model of the SAMS GCA with the integrated maintenance and repair system describes the processes of changing the technical state of the SAMS GCA taking into account the level of reliability, periodic FC, and maintenance and restora- 
tions of the operational state (current repairs) at the intervals between FC and maintenance during the long-term operation.

This model is represented by the instantaneous availability factor IAF, which is the probability that at any $t_{\mathrm{e}}$ moment of operation SAMS GCA are operable. This factor is calculated as follows:

$$
K_{\mathrm{IAF}}\left(t_{\mathrm{e}}\right)=P_{1}\left(t_{\mathrm{e}}\right) P_{2}\left(t_{\mathrm{e}}\right) P_{3}\left(t_{\mathrm{e}}\right)
$$

where $P_{1}\left(t_{\mathrm{e}}\right)$ - the probability of SAMS GCA operating state at any $t_{\mathrm{e}}$ time according to the components which are not checked during maintenance and FC; $P_{2}\left(t_{\mathrm{e}}\right)-$ the probability of SAMS GCA operating state between maintenances according to the components which are not controlled during maintenance and $\mathrm{FC} ; P_{3}\left(t_{\mathrm{e}}\right)-$ the probability of SAMS GCA operating state between FC according to of the components which are not checked during FC, but are controlled during maintenance.

In this case it is supposed that control completeness factors at maintenance $-k_{\mathrm{n} 2}$ and at $\mathrm{FC}-k_{\mathrm{n} 1}$ are known, when $k_{\mathrm{n} 2}>k_{\mathrm{n} 1}$. Control completeness factors mean failure intensity ratio of a SAMS GCA part that is controlled to failure intensity of the whole SAMS GCA.

$P_{1}\left(t_{\mathrm{e}}\right)$ and $P_{2}\left(t_{\mathrm{e}}\right)$ probabilities are calculated as follows:

$$
\begin{gathered}
P_{1}\left(t_{\mathrm{e}}\right)=\mathrm{e}^{-\left(1-k_{\mathrm{m} 2}\right) \lambda\left(t_{\mathrm{e}}\right) t_{\mathrm{e}}} \\
P_{2}\left(t_{\mathrm{e}}\right)=\mathrm{e}^{-\left(k_{\mathrm{m} 2}-k_{\mathrm{m} 1}\right) \lambda\left(t_{\mathrm{e}}\right)\left[t_{\mathrm{e}}-T_{\mathrm{m}} N_{\mathrm{m}}\left(t_{\mathrm{e}}\right)\right]}
\end{gathered}
$$

where $\mathrm{N}_{\mathrm{m}}\left(t_{\mathrm{e}}\right)$ - the quantity of maintenances at $t_{\mathrm{e}}$ is calculated as follows:

$$
N_{\mathrm{m}}\left(t_{\mathrm{e}}\right)=\operatorname{ent}\left[\frac{t_{\mathrm{e}}}{T_{\mathrm{m}}}\right]
$$

where ent $[x]$ - the integer part of number.

$P_{3}\left(t_{\mathrm{e}}\right)$ the probability is calculated as follows:

$$
P_{3}\left(t_{\mathrm{e}}\right)=\mathrm{e}^{-k_{n 1} \lambda\left(t_{\mathrm{e}}\right)\left[t_{\mathrm{e}}-T_{\mathrm{m}} N_{\mathrm{m}}\left(t_{\mathrm{e}}\right)-N_{\mathrm{fc}}\left(t_{\mathrm{e}}\right) T_{\mathrm{fc}}\right]}
$$

where $T_{\mathrm{fc}}-$ the FC frequency; $N_{\mathrm{fc}}\left(t_{\mathrm{e}}\right)$ - the quantity of FC since last maintenance until current $t_{\mathrm{e}}$ calculated as follows:

$$
N_{\text {fc }}\left(t_{\mathrm{e}}\right)=\operatorname{ent}\left[\frac{t_{\mathrm{e}}-\left[N_{\mathrm{m}}\left(t_{\mathrm{e}}\right) T_{\mathrm{m}}\right]}{T_{\mathrm{fc}}}\right]
$$

According to the model, in case of GCA failure during FC and maintenance, their operation is restored and all revealed defects are eliminated.

The considered models of operation of SAMS GCA according to the typical cyclogram of the intended use and a model of the dynamics of the reliability of SAMS GCA with the integrated maintenance and repair system are used to calculate the IAF. This factor indicates the probability that SAMS GCA at the time of assignment of the target are operational, provided that at the time of the announcement of readiness, they were in a known initial operational state. The formula for calculating the IAF is as follows: 


$$
\begin{aligned}
K_{\mathrm{IAFR}}\left(t_{\mathrm{e}}, t_{\mathrm{sby}}\right)= & K_{\mathrm{IAF}}\left(t_{\mathrm{e}}\right)\left\{P_{\mathrm{E} 1}\left(t_{\mathrm{e}}\right) P_{y}\left(t_{\mathrm{e}}\right)+\left[P_{\mathrm{E} 2}\left(t_{\mathrm{e}}\right)+P_{\mathrm{E} 4}\left(t_{\mathrm{e}}\right)+P_{\mathrm{E} 5}\left(t_{\mathrm{e}}\right)\right]\right\} \\
& K_{\mathrm{IAF}}\left(t_{\mathrm{e}}, t_{\mathrm{sby}}\right)+\left\{\left[1-K_{\mathrm{IAF}}\left(t_{\mathrm{e}}\right)\right]\left[1-P_{\mathrm{E} 3}\left(t_{\mathrm{e}}\right)\right]+P_{\mathrm{E} 3}\left(t_{\mathrm{e}}\right)\right\} K_{\mathrm{IAF}}^{0}\left(t_{\mathrm{e}}, t_{\mathrm{sby}}\right)
\end{aligned}
$$

where $t_{\text {sby }}$ - the combat standby time; $K_{\text {IAF }}^{0}\left(t_{\mathrm{e}}, t_{\text {sby }}\right)[16]$ and $K_{\text {IAF }}\left(t_{\mathrm{e}}, t_{\text {sby }}\right)-$ IAF of SAMS GCA at initial non-operational and operational states respectively, which consider possible failures and operation restorations at combat standby mode $t_{\text {sby }}$ [19].

IAF of operational readiness (IAFOR) of SAMS GCA that additionally to IAFOR considers the probability of SAMS GCA non-failure operation during air combat is calculated as follows:

$$
K_{\mathrm{IAFOR}}\left(t_{\mathrm{e}}, t_{\mathrm{sby}}, t_{\mathrm{cw}}\right)=K_{\mathrm{IAFR}}\left(t_{\mathrm{e}}, t_{\mathrm{sby}}\right) P_{\mathrm{GCA}}\left(t_{\mathrm{cw}}\right)
$$

where $P_{\mathrm{GCA}}\left(t_{\mathrm{cw}}\right)$ - probability of SAMS GCA non-failure work during combat $-t_{\mathrm{cw}}$.

The model of dynamics of reliability indicators of guided surface-to-air missiles at long-term operation characterizes a reliability of guided SAMs which represent a part of SAMS.

The model is represented by two indicators:

- the probability that the $r$-SAM, which are put on pre-launch training, at least $n$ will be recognized as ready for use in combat operations, as determined as follows:

$$
P_{r, n}\left(t_{\mathrm{e}}\right)=\sum_{i=n}^{r} C_{r}^{i} P_{\mathrm{pp}}^{i}\left(t_{\mathrm{e}}\right)\left[1-P_{\mathrm{pp}}\left(t_{\mathrm{e}}\right)\right]^{r-i}
$$

where $P_{\mathrm{pp}}\left(t_{\mathrm{e}}\right)$ - the probability that one SAM, which is put on pre-launch preparation, will be considered as ready for use in combat operations; $C_{r}^{i}-$ binomial coefficient,

- the probability of failure-free operation of the SAM during the $t_{\mathrm{f}}$ flight time $P_{\mathrm{f}}\left(t_{\mathrm{e}}, t_{\mathrm{f}}\right)$.

Dependences $P_{\mathrm{pp}}\left(t_{\mathrm{e}}\right)$ and $P_{\mathrm{f}}\left(t_{\mathrm{e}}, t_{\mathrm{f}}\right)$ on $t_{\mathrm{e}}$ could be based on the results of point estimate of these indicators, which are obtained based on the results of SAM operational observations and tests during works on assigned indicators extension. Pairwise regressional dependences are constructed based on point estimates [19]:

$$
\begin{gathered}
P_{\mathrm{pp}}\left(t_{\mathrm{e}}\right)=c_{0}+c_{1} t_{\mathrm{e}}+c_{2} t_{\mathrm{e}}^{2}+\ldots+c_{k} t_{\mathrm{e}}^{k} \\
P_{f}\left(t_{\mathrm{e}}, t_{\mathrm{f}}\right)\left(t_{\mathrm{e}}, t_{\mathrm{f}}\right)=d_{0}+d_{1} t_{\mathrm{e}}+d_{2} t_{\mathrm{e}}^{2}+\ldots+d_{m} t_{\mathrm{e}}^{m}
\end{gathered}
$$

where $c_{0}, c_{1}, \ldots, c_{k} ; d_{0}, d_{1}, \ldots, d_{k}$ - polynomial coefficients.

Then the mathematical model for the calculation of the SAMS OTI $K_{\text {eff }}$ is as follows [13]:

$$
K_{\text {eff }}\left(t_{\mathrm{e}}, t_{\mathrm{cw}}, t_{\mathrm{f}}\right)\left(t_{\mathrm{e}}, t_{\mathrm{cw}}, t_{\mathrm{f}}\right)=K_{\mathrm{IAFOR}}\left(t_{\mathrm{e}}, t_{\mathrm{cw}}\right) P_{r, n}\left(t_{\mathrm{e}}\right) \frac{1-\left[1-P_{\mathrm{f}}\left(t_{\mathrm{e}}, t_{\mathrm{f}}\right) P_{1}\right]^{n}}{1-\left[1-P_{1}\right]^{n}}
$$

where $P_{1}-$ the probability of target destruction by one SAM.

The following are the results of the dependence modeling $K_{\mathrm{eff}}\left(t_{\mathrm{e}}, \mathrm{t}_{\mathrm{cw}}, t_{\mathrm{f}}\right)$ in accordance with the relationship (20) in the following initial data: 
$T_{\mathrm{m}}=0.5$ year; $T_{\mathrm{fc}}=24$ hour; $t_{\mathrm{m}}=7$ days; $t_{\mathrm{fc}}=0.25$ hour; $T_{\mathrm{c}}=2$ year; $k_{\mathrm{ie}}=0.05 ;$ $k_{n 1}=0.95 ; k_{n 2}=0.999 ; f_{\mathrm{y}}=0.042$ switching on per hour ${ }^{-1} ; t_{\mathrm{cw}}\left(t_{\mathrm{e}}, T_{\mathrm{c}}\right)=0.5$ hour; $T_{\mathrm{tr}}=7$ days; $t_{\mathrm{tr}}=0.5$ hour; $T_{\text {art }}\left(t_{\mathrm{e}}\right)=1.5$ hour, at $t_{\mathrm{e}}$ to 12 years; $T_{\text {art }}\left(t_{\mathrm{e}}\right)=3$ hours, at $t_{\mathrm{e}}$ from 12 to 20 years; $T_{\text {art }}\left(t_{\mathrm{e}}\right)=6$ hours, at $t_{\mathrm{e}}$ from 20 to 30 years; $r=3 ; n=2 ; P_{1}=0.7$; the maximum calendar time of SAMS in service is 30 years.

For these input data, the ratio to calculate $\lambda_{\mathrm{on}}\left(t_{\mathrm{e}}\right), P_{\mathrm{y}}\left(t_{\mathrm{e}}\right), P_{\mathrm{pp}}\left(t_{\mathrm{e}}\right)$ and $P_{\mathrm{f}}\left(t_{\mathrm{e}}, t_{\mathrm{f}}\right)$ is as follows:

$$
\begin{gathered}
\lambda_{\mathrm{on}}\left(t_{\mathrm{e}}\right)=0.023+1.087 \cdot 10^{-4} t_{\mathrm{e}}-1.19 \cdot 10^{-6} t_{\mathrm{e}}^{2} \\
P_{y}\left(t_{\mathrm{e}}\right)=0.995-5 \cdot 10^{-7} t_{\mathrm{e}} \\
P_{\mathrm{pp}}\left(t_{\mathrm{e}}\right)=0.961-7.377 \cdot 10^{-5} t_{\mathrm{e}}-1.42 \cdot 10^{-6} t_{\mathrm{e}}^{2} \\
P_{\mathrm{f}}\left(t_{\mathrm{e}}, t_{\mathrm{f}}\right)=0.899+3.773 \cdot 10^{-5} t_{\mathrm{e}}-4.029 \cdot 10^{-6} t_{\mathrm{e}}^{2}
\end{gathered}
$$

where $t_{\mathrm{e}}$ - the calendar time in service in hours.

The following limitations are set in modeling:

- one type of periodic maintenance, which is equal to 0.5 year, is taken into account,

- periodic repairs defined for SAMS GCA were not performed,

- SAMs are products which are not checked, serviced and restored during operation.

Fig. 1 shows the graph of dependence of SAMS OTI $K_{\text {eff }}$ in the form of a volume surface on calendar time of SAMS GCA and SAM in service calculated based on relationship (20) at the above-mentioned initial data. The graph shows that the significant value decreases $K_{\mathrm{eff}}\left(t_{\mathrm{e}}, \mathrm{t}_{\mathrm{cw}}, t_{\mathrm{f}}\right)$ with increase of service life $t_{\mathrm{e}}$ GCA and $t_{\mathrm{e}} \mathrm{SAM}$. This is due to the changes of indicators $K_{\mathrm{IAFOR}}\left(t_{\mathrm{e}}, \mathrm{t}_{\mathrm{sby}}, t_{\mathrm{cw}}\right), P_{r, n}\left(t_{\mathrm{e}}\right)$ and $P_{\mathrm{f}}\left(t_{\mathrm{e}}, \mathrm{t}_{\mathrm{f}}\right)$.

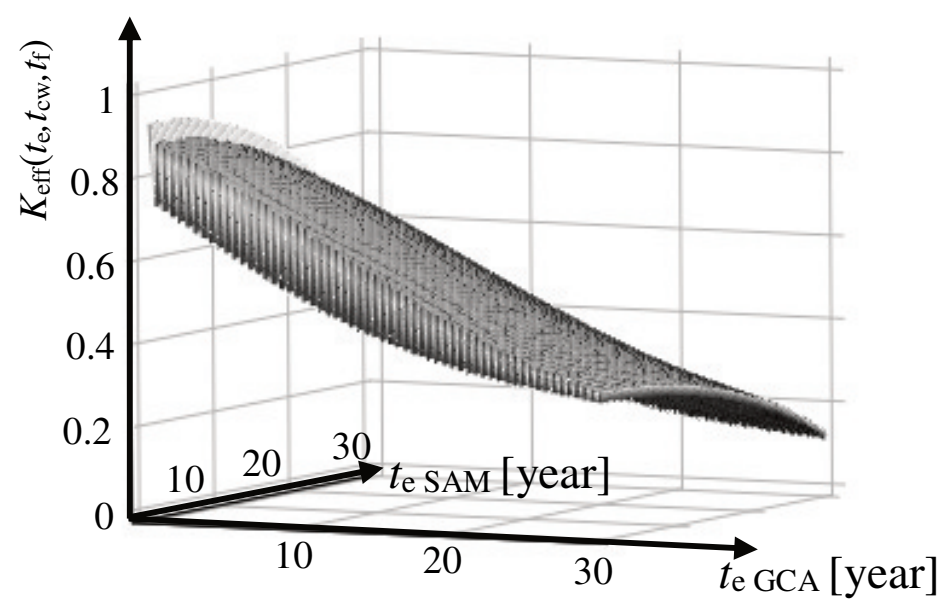

Fig. 1 Dependence of the operational and tactical indicator $K_{\mathrm{eff}}$ of the surface-to-air missile system on $t_{\mathrm{e}} \mathrm{GCA}, t_{\mathrm{e}} \mathrm{SAM}$ 
The analysis of the graph of this dependence shows the following:

- the graph of dependence of SAMS OTI $K_{\text {eff }}$ on GCA service time along the axis $t_{\mathrm{e}} \mathrm{GCA}$ is decreasing sawshaped. It is caused by the reduction of failure-free level of SAMS GCA at the intervals between periodic FC and maintenance and restoration of operation based on the control results, if necessary,

- the graph of the dependence of SAMS OTI $K_{\text {eff }}$ on GCA service time along the axis $t_{\mathrm{e}}$ SAM is smooth downline. It is caused by the reduction of failure-free level of SAMS GCA with the increase of service time and absent SAM control, periodic maintenance and routine repairs,

- the downline level of dependence, which envelopes the conditioned component $P_{1}\left(t_{\mathrm{e}}\right)$ resulted from the decrease of failure-free level caused by absent periodic repairs and increase of defects number which are not revealed during FC and maintenance.

Fig. 2 shows the graphs of SAMS OTI $K_{\text {eff }}$ dependences on SAMS GCA service time at fixed values of SAM reliability indicators $-P_{\mathrm{pp}}\left(t_{\mathrm{e}}\right)$ and $P_{\mathrm{f}}\left(t_{\mathrm{e}}, t_{\mathrm{f}}\right)$.

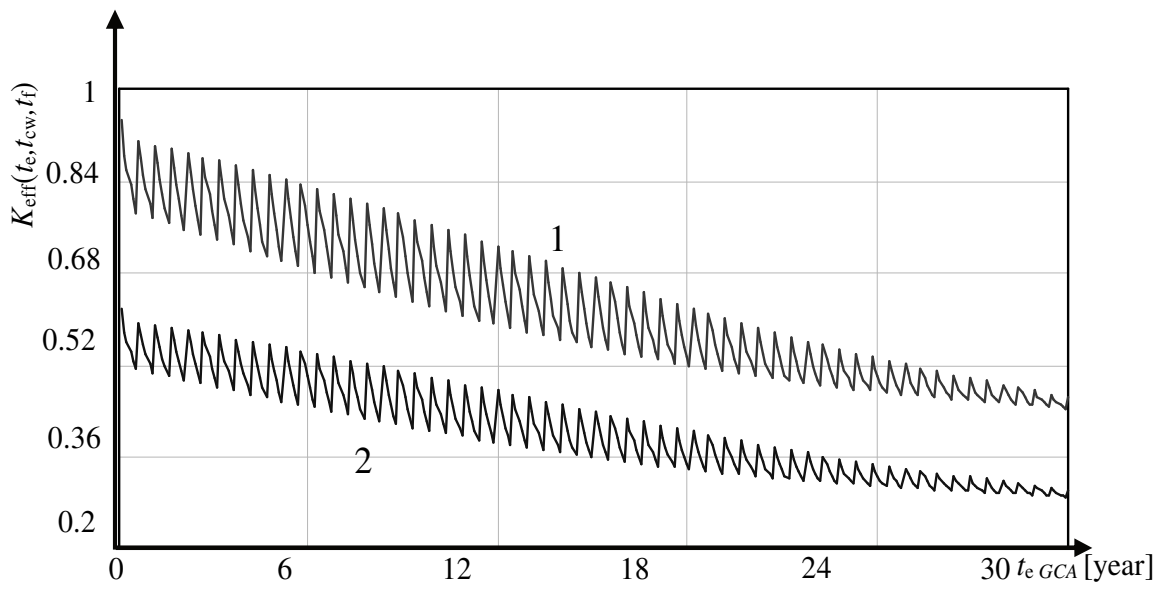

Fig. 2 The graph of the dependence of $K_{\text {eff }}$ of the surface-to-air missile system on service time of SAMS GCA at fixed values of SAM reliability indicators:

1 - when operating SAM of $1 \ldots 2$ years; 2 - when operating SAM of $28 \ldots 30$ years

The graphs analysis of these dependences is as follows:

- when operating a SAM of $t_{\mathrm{e} 1}=1 \ldots 2$ years with reliability indicators $P_{\mathrm{pp}}\left(t_{\mathrm{e} 1}\right)=0.95$ and $P_{\mathrm{f}}\left(t_{\mathrm{e} 1}, t_{\mathrm{f}}\right)=0.89$ within the SAMS, the value of the SAMS OTI $K_{\text {eff }}$ decreases from 0.9 at the $1^{\text {st }}$ year of operation to 0.5 at the $30^{\text {th }}$ year of operation. It is caused by the decrease of the level of reliability of the SAMS GCA without scheduled repairs,

- when operating a SAM of $t_{\mathrm{e} 2}=28 \ldots 30$ years with reliability indicators $P_{\mathrm{pp}}\left(t_{\mathrm{e} 2}\right)=0.67$ and $P_{\mathrm{f}}\left(t_{\mathrm{e} 2}, \mathrm{t}_{\mathrm{f}}\right)=0.5$ within the SAMS, the value of the SAMS OTI $K_{\text {eff }}$ decreases from 0.6 at the $1^{\text {st }}$ year of operation to 0.3 in the $30^{\text {th }}$ year of operation. It is caused by the decrease of the level of reliability of both SAMS GCA and SAM,

- the sawshaped dependence of the SAMS OTI $K_{\text {eff }}$ on the service time shows that during the FC or maintenance, the level of reliability of the 
SAMS GCA increases due to restoration of their operational state according to the control results.

In order to assess the impact of the considered factors significance, the SAMS OTI $K_{\text {eff }}$ for three calendar times of SAMS service are calculated below. For this purpose, the conventional stock of SAMS GCA and SAM is divided into homogeneous groups of products depending on their calendar time in service and reliability level, namely into three groups of SAMS GCA and three groups of SAM:

- group 1 - SAMS GCA or SAM with calendar time in service maximum 1 year,

- group 2 - SAMS GCA or SAM with calendar time in service of 15-16 years,

- group 3 - SAMS GCA or SAM with calendar time in service of 29-30 years.

Every group of SAMS GCA or SAM is characterized by the corresponding values of reliability indicators, which are considered as a function of the calendar time in service.

Tab. 1 below shows the results of SAMS $K_{\text {eff }}\left(t_{\mathrm{e}}, \mathrm{t}_{\mathrm{cw}}, t_{\mathrm{f}}\right)$, calculation obtained in accordance with the ratio (20) at $t_{\text {sby }}=0.25$ hour and $t_{\text {sby }}=1.5$ hour for different combinations of groups of SAMS GCA or SAM.

Tab. 1 The results of SAMS OTI $K_{\mathrm{eff}}$ calculation

\begin{tabular}{|c|c|c|c|c|c|c|}
\hline \multirow{2}{*}{$\begin{array}{c}\text { Groups } \\
\text { of } \\
\text { SAMS }\end{array}$} & \multicolumn{5}{|c|}{ Groups of SAM } \\
\cline { 2 - 7 } \begin{tabular}{c} 
GCA \\
\cline { 2 - 7 }
\end{tabular} & \multicolumn{2}{|c|}{1} & \multicolumn{2}{|c|}{2} & \multicolumn{2}{c|}{3} \\
\cline { 2 - 7 } sby [hour] & \multicolumn{2}{|c|}{$t_{\text {sby }}[$ hour] } & \multicolumn{2}{c|}{$t_{\text {sby }}[$ hour] } \\
\hline \hline 1 & 0.25 & 1.5 & 0.25 & 1.5 & 0.25 & 1.5 \\
\hline 2 & 0.89 & 0.92 & 0.82 & 0.85 & 0.58 & 0.6 \\
\hline 3 & 0.45 & 0.83 & 0.42 & 0.75 & 0.3 & 0.53 \\
\hline
\end{tabular}

The results of SAMS OTI $K_{\text {eff }}$ calculations shown in Tab. 1 prove that during long-term operation, the change of SAMS OTI $K_{\text {eff }}$ is significant and can vary from 0.92 at $=1$ year to 0.19 at $=29-30$ years in the absence of scheduled repairs of SAMS GCA or SAM.

It should be noticed that the combat standby time $t_{\text {sby }}$ significantly influences the effectiveness of GCA used for 15 years or more. The SAMS OTI $K_{\text {eff }}$ of the $3^{\text {rd }}$ group components varies from 0.5 at $t_{\text {sby }}=1.5$ hour to 0.19 at $t_{\text {sby }}=0.25$ hour. This is because SAMS GCA are more likely to be inoperable at the beginning of the standby interval.

\section{Conclusions}

The article provides the designed model of SAMS reliability at long-term operation that appropriately reflects TCIU features and defined maintenance and repair system. The results of the experiment/research have been proved by the fact that the changeable feature of SAMS OTI $K_{\text {eff }}$ dependence on the duration of life cycle corresponds to an expectable one. Another proof of the results has been provided by 
the results of the evaluation of indicators of SAMS GCA and SAM reliability during their long-term operation.

The designed model provides for its development in terms of objects with different periods of maintenance and repair.

The designed model is practically valuable during the design of prospective SAMSs, the modernization of existing ones, as well as during the maintenance and repair of existing ones. In practice, the designed model should be used by:

- senior engineering staff at the stage of research or design decision-making to substantiate the requirements for reliability indicators of SAMS GCA and SAM for their design or modernization, based on the requirements for SAMS OTI $K_{\text {eff }}$, taking into account the TCIU features and maintenance and repair systems,

- senior engineering staff at the operational stage when developing the repair plans for SAMS GCA and SAM, in particular, when determining the moment of their withdrawal for repair according to the criterion of reduction of functioning efficiency of SAMS below the limit value during planning of logistical support of military units of anti-aircraft missile forces,

- command staff to develop methods for assessing the effectiveness of the SAMS, taking into account the life cycle duration of the SAMS GCA and SAM in combat documents (for example, in the field manual) for further use during the planning of combat use by anti-aircraft missile forces.

Furthermore, the designed model should be used to solve the above-mentioned tasks for CTS of other purposes, the typical cyclogram of use of which includes monitoring of technical condition, restoration of serviceability, maintenance and repairs.

\section{References}

[1] NAPIÓRKOWSKIA, J. and J. GONERA. Analysis of Failures and Reliability Model of Farm Tractors. Agricultural Engineering, 2020, 24(2), pp. 89-101. DOI 10.1515/agriceng-2020-0020.

[2] CUI, L., Y. LI, J. SHENA and L. CONG. Reliability Evaluation Based on a Dependent Two-Stage Failure Process with Competing Failures. Applied Mathematical Modelling, 2018, 64, pp. 699-712. DOI 10.1016/j.apm.2018.07.39.

[3] PRAKS, P., V. KOPUSTINSKAS and M. MASERA. Monte-Carlo-Based Reliability and Vulnerability Assessment of a Natural Gas Transmission System Due to Random Network Component Failures. Sustainable and Resilient Infrastructure, 2017, 2, pp. 97-107. DOI 10.1080/23789689.2017.1294881.

[4] YANG, J., J. CHEN, Y. HUO and Y. LIU. A Novel Cluster-Based Wireless Sensor Network Reliability Model Using the Expectation Maximization Algorithm. Journal of Sensors, 2021, 2021, pp. 1-13. DOI $10.1155 / 2021 / 8869544$.

[5] TORRES, E.S., S. SRIRAMULA, D. CELEITA and G. RAMOS. Reliability Model and Sensitivity Analysis for Electrical/Electronic/Programmable Electronic Safety-Related Systems. IEEE Transactions on Industry Applications, 2020, 56(4), pp. 3422-3430. DOI 10.1109/TIA.2020.2990583.

[6] ZUBAREV, V.V., A.P. KOVTUNENKO, A.V. VASILENKO, I.B. CHEPKOV and M.A. SHISHANOV. Foundations of the Theory of Complex Substantiation 
of Requirements for Technical Indicators of Complex Systems [in Russian]. Kyiv: Knizhkove vidavnitstvo NAU, 2010. ISBN 978-966-2377-11-8.

[7] KOVTUNENKO, A.P., V.V. ZUBAREV, B.N. LANETSKIY and A.A. ZVEREV. Mathematical Modeling in Problems of Research of Reliability of a Technical Systems [in Russian]. Kyiv: Knizhkove vidavnitstvo NAU, 2006. ISBN 978-966598-306-4.

[8] MUSCOLINO, G., R. SANTORO and A. SOFI. Reliability Analysis of Structures with Interval Uncertainties under Stationary Stochastic Excitations. Computer Methods Applied Mechanics and Engineering, 2016, 300, pp. 47-69. DOI 10.1016/j.cma.2015.10.023.

[9] TOBIAS, P.A. and D.C. TRINDADE. Applied Reliability. $3^{\text {rd }}$ ed. Boca Raton: CRC Press, 2012. ISBN 978-1-58488-466-5.

[10] LANETSKII, B.N., V.V. LUKYANCHUK and A.A. ARTEMENKO. Comprehensive Assessment of Indicators of Reliability and Residual Durability of Complex Technical Systems Operated According to Their Technical Condition. Fundamentals [in Russian]. Information Processing Systems, 2016, 2(139), pp. 40-43. ISSN 1681-7710.

[11] OPEN'KO, P.V., P.A. DRANNYK, V.V. KOBZEV, M.B. BROVKO and G.S. ZALEVSKY. Substantiation of Reliability Requirements for Mobility Means of Surface-to-Air Missile Systems. Advances in Military Technology, 2017, 12(1), pp. 91-99. DOI 10.3849/aimt.01122.

[12] OPEN'KO, P.V., V.V. TYURIN, M.Y. MIRONYUK, P.A. DRANNYK and V.V. KOBZEV. Reliability and Maintainability Requirements for Mobility Means of Surface-to-Air Missile Systems. Advances in Military Technology, 2020, 15(2), pp. 425-434. DOI 10.3849/aimt.01402.

[13] LANETSKII, B.N., I.V. KOVAL, V.V. LUKYANCHUK and V.P. POPOV. Method for Predicting the Influence of Changes in the Technical State of the Main Samples of Anti-Aircraft Missile System on the Efficiency of Their Functioning During Long-Term Operation [in Ukrainian]. Armament and Military Equipment, 2020, 3(27), pp. 50-55. DOI 1034169/2414-0651.

[14] ADMP-01:2014, Guidance for Developing Dependability Requirements - Edition A Version 1.-14.

[15] ADMP-02:2014, Guidance for Dependability In-Servise - Edition A Version 1.-15.

[16] LANETSKII, B., V. LUKYANCHUK, H. KHUDOV, M. FISUN, O. ZVIERIEV and I. TEREBUHA. Developing the Model of Reliability of a Complex Technical System of Repeated Use with a Complex Operating Mode. Eastern-European Journal of Enterprise Technologies, 2020, 4(107), pp. 55-65. DOI 10.15587/ 1729-4061.2020.214995.

[17] DREJPER N.R. and H. SMITH. Applied Regression Analysis. $3^{\text {rd }}$ ed. Hoboken: Wiley, 1998. ISBN 978-0-471-17082-2.

[18] ADUEVSKIJ, V.S. ed. Reliability and Efficiency in Technology [in Russian]. Moscow: Mashinostroenie, 1990.

[19] BEICHELT, F. and P. FRANKEN. Reliability and Maintenance-Mathematical Methods [in German]. Berlin: Verlag Technik, 1983. 